\title{
Modeling of an Inductive Adder Kicker Pulser for A Proton Radiography System
}

\author{
L. Wang, G. L. Caporaso, E. G. Cook
}

This article was submitted to 2001 The Institute of Electrical and Electronics Engineers, Inc. International Pulsed Power Plasma Science Conference, Las Vegas, NV., June 17-22, 2001

U.S. Department of Energy

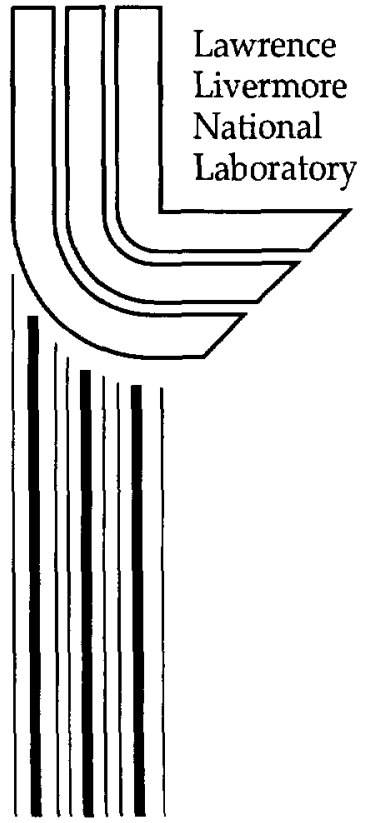

\section{June 12, 2001}




\section{DISCLAIMER}

This document was prepared as an account of work sponsored by an agency of the United States Government. Neither the United States Government nor the University of California nor any of their employees, makes any warranty, express or implied, or assumes any legal liability or responsibility for the accuracy, completeness, or usefulness of any information, apparatus, product, or process disclosed, or represents that its use would not infringe privately owned rights. Reference herein to any specific commercial product, process, or service by trade name, trademark, manufacturer, or otherwise, does not necessarily constitute or imply its endorsement, recommendation, or favoring by the United States Government or the University of California. The views and opinions of authors expressed herein do not necessarily state or reflect those of the United States Government or the University of California, and shall not be used for advertising or product endorsement purposes.

This is a preprint of a paper intended for publication in a journal or proceedings. Since changes may be made before publication, this preprint is made available with the understanding that it will not be cited or reproduced without the permission of the author.

This work was performed under the auspices of the United States Department of Energy by the University of California, Lawrence Livermore National Laboratory under contract No. W-7405-Eng-48.

This report has been reproduced directly from the best available copy.

Available electronically at http://www.doc.gov/bridge

Available for a processing fee to U.S. Department of Energy

And its contractors in paper from

U.S. Department of Energy

Office of Scientific and Technical Information

P.O. Box 62

Oak Ridge, TN 37831-0062

Telephone: (865) 576-8401

Facsimile: (865) 576-5728

E-mail: reports@adonis.osti.gov

Available for the sale to the public from

U.S. Department of Commerce

National Technical Information Service

5285 Port Royal Road

Springfield, VA 22161

Telephone: (800) 553-6847

Facsimile: (703) 605-6900

E-mail: orders@ntis.fedworld.gov

Online ordering: http://www.ntis.gov/ordering.htm

OR

Lawrence Livermore National Laboratory

Technical Information Department's Digital Library

http://www.llnl.gov/tid/Library.html 


\title{
MODELING OF AN INDUCTIVE ADDER KICKER PULSER FOR A PROTON RADIOGRAPHY SYSTEM*
}

\author{
L. Wang ${ }^{\xi}$, G. J. Caporaso, E. G. Cook \\ LLNL, L-645 \\ Livermore, CA94550, USA
}

\begin{abstract}
An all solid-state kicker pulser for a proton radiography system has been designed. Multiple solid-state modulators stacked in an inductive-adder configuration are utilized in this kicker pulser design. Each modulator is comprised of multiple metal-oxide-semiconductor field-effect transistors (MOSFETs) which quickly switch the energy storage capacitors across a magnetic induction core. Metglas is used as the core material to minimize loss. Voltage from each modulator is inductively added by a voltage summing stalk. A circuit model of a prototype inductive adder kicker pulser modulator has been developed to predict the performance of the pulser modulator. The modeling results are compared with experimental data.
\end{abstract}

\section{I.INTRODUCTION}

A proton radiography system can provide time-resolved, 3-D radiography capabilities for a hydrodynamic event. For a proton machine with acceleration by synchrotrons, a flexible extraction system which is capable of extracting individual proton bunches in the ring at arbitrary times is needed. This requires a kicker modulator with fast switches that can open under load. The closest technology to meet this requirement is the modulator design approach developed at LLNL for Dual-Axis Radiographic Hydrodynamic Test facility (DARHT-II) [1]. The original design of the pulser was based on planar triodes [2]. Although the performance of the pulser based on this design was very good, the availability of the high frequency planar triodes in the future has become a concern. This led to the development of an all solid-state kicker pulser design for DARHT-II (Figure 1). The new pulser design was based on the Advanced Radiograph Machine (ARM) modulator technology [3]. It uses multiple solid-state modulators stacked in an inductiveadder configuration. This modular design approach facilitates scale-up to meet the needs of the proton radiography system.

Prototype kicker pulser modulator boards for the proton

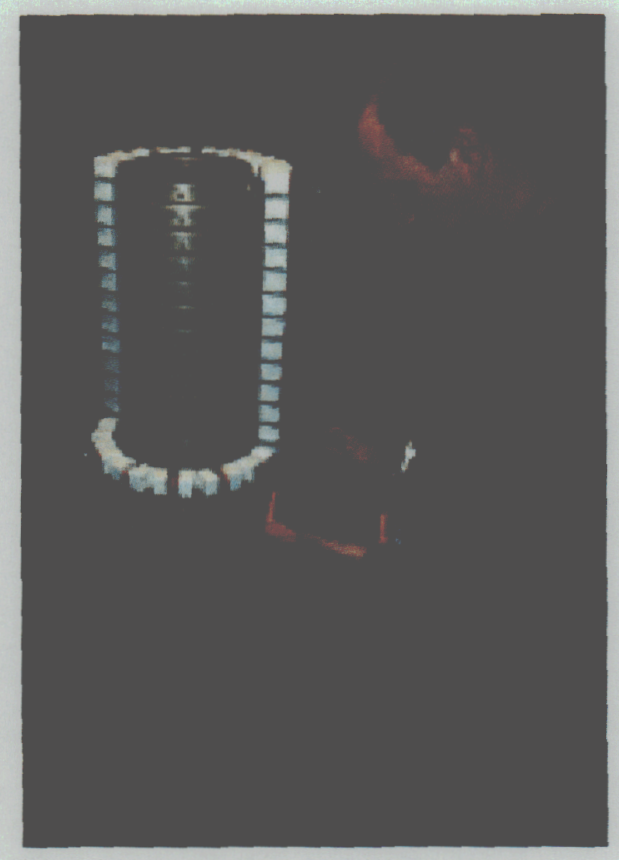

Figure 1. DARHT-II inductive adder kicker pulser.

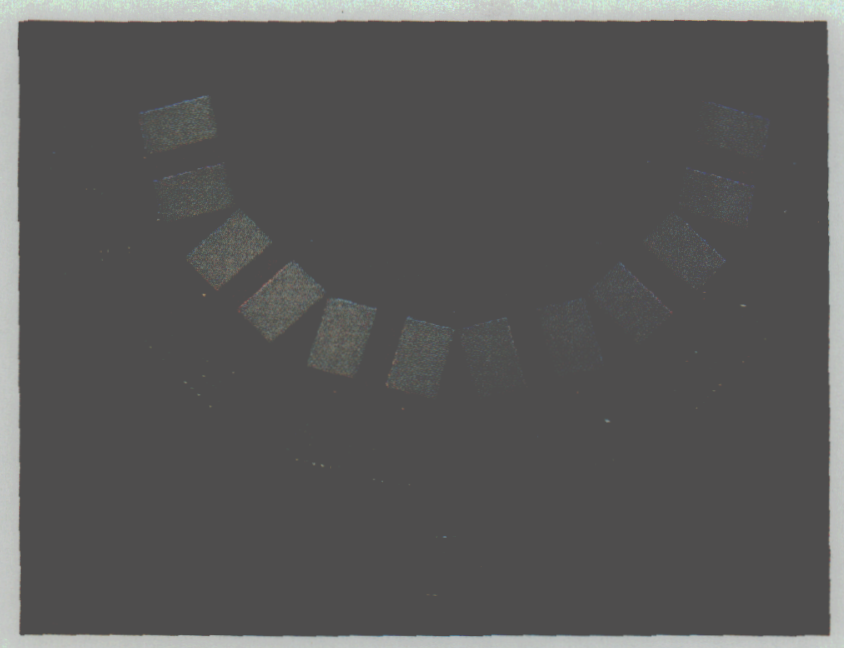

Figure 2. A prototype kicker pulser modulator board.

\footnotetext{
- The work was performed under the auspices of the U.S. Department of Energy by University of California Lawrence Livermore National Laboratory under contract No. W-7405-Eng-48

ร email: wang22@llnl.gov
} 
radiography system have been fabricated and tested (Figure 2). Each modulator is comprised of multiple power metaloxide-semiconductor field-effect transistors (MOSFETs) which were selected as the switching device. They can quickly switch the energy storage capacitors across a magnetic induction core. Metglas is used as the core material to minimize loss. Voltage from each modulator is inductively added by a voltage summing stalk. The cross section of this solid-state kicker pulser is shown in Figure 3. For the purpose of illustration, only three stacked modules are shown in the figure. On each stack, there are two modulator boards with twelve MOSFETs on each board. The secondary winding is a metal rod which is placed on the centerline of the kicker pulser. The rod can be grounded at either end to generate a positive or a negative output voltage.

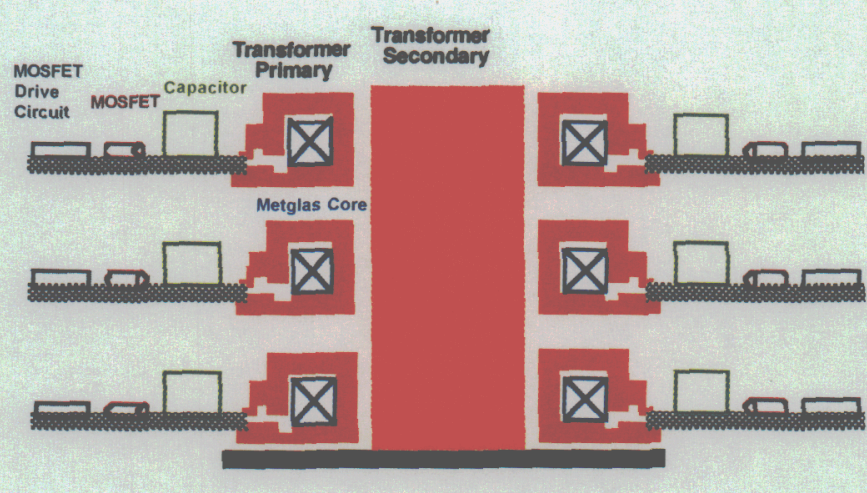

Figure 3. Cross section of the solid-state kicker pulser.

\section{II.CIRCUIT MODEL OF A PROTOTYPE KICKER PULSER MODULATOR}

A lumped element circuit model of the inductive adder kicker pulser modulator has been developed to simulate the output voltage waveform. Figure 4 shows the circuit model of a prototype kicker pulser modulator board. In the figure, $\mathrm{X} 1, \mathrm{X} 2, \mathrm{X} 3, \mathrm{X} 4, \mathrm{X} 5$, and $\mathrm{X} 6$ are sub-circuits. $\mathrm{K} 1$ is a transformer with $1: 1$ turns ratio. A circuit diagram of the sub-circuits is shown in Figure 5. Each sub-circuit is comprised of two MOSFETs M1 and M2, and two energy storage capacitors $\mathrm{C1}$ and C2. MOSFETs are modeled based on the data sheet provided by the manufacturer. The resistance and inductance associated with each capacitor are included in the circuit model. They are about $0.005 \mathrm{Ohms}$ and $15 \mathrm{nH}$, respectively. The $0.22 \mathrm{uF}$ capacitor and the diode D1 connected in series provide protection for the MOSFETs against overvoltage transient which can be generated by the energy stored in the primary of the transformer and the stray loop inductance. The $0.22 \mathrm{uF}$ capacitor is initially charged to the same voltage as the energy storage capacitors. When the MOSFET is turned on, the diode $\mathrm{D} 1$ is off. Therefore, the $0.22 \mathrm{uF}$ capacitor is prevented from discharging through the MOSFET. When the MOSFET is turned off, the transient voltage which may exceed the $0.22 \mathrm{uF}$ capacitor voltage turns the diode on such that the capacitor can absorb the energy. The resistor parallel to the diode allows the excess capacitor voltage to discharge into the energy storage capacitor between bursts.

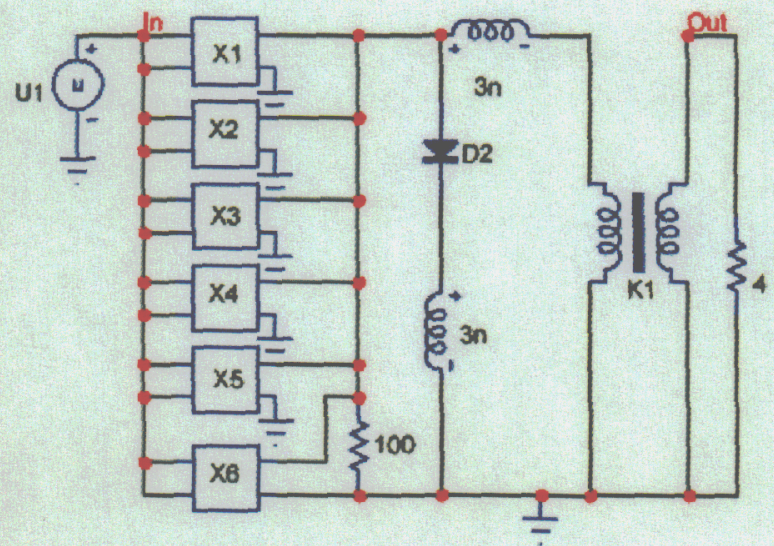

Figure 4. Circuit model of a prototype kicker pulser modulator board.

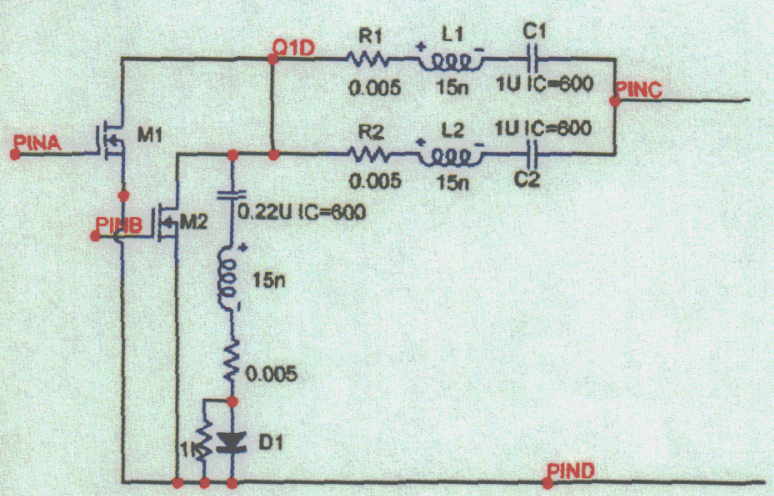

Figure 5. Circuit diagram of $X 1, X 2, X 3, X 4, X 5, X 6$ sub-circuits shown in Figure 4.

\section{III.SIMULATION RESULTS}

Output voltage waveforms are simulated using the circuit model for different pulse widths. Input waveforms at the gate terminal of a MOSFET are obtained from the experimental measurements. The digitized voltage waveform is then used in the input wave generator U1 in the circuit during simulation. Figure 6 shows the 75ns input pulse at the gate terminal of a MOSFET.

For the case of $75 \mathrm{~ns}$ input pulse, the capacitors are charged to $600 \mathrm{~V}$ initially. The simulated voltage 
waveform at the drain terminal of a MOSFET is displayed in Figure 7.

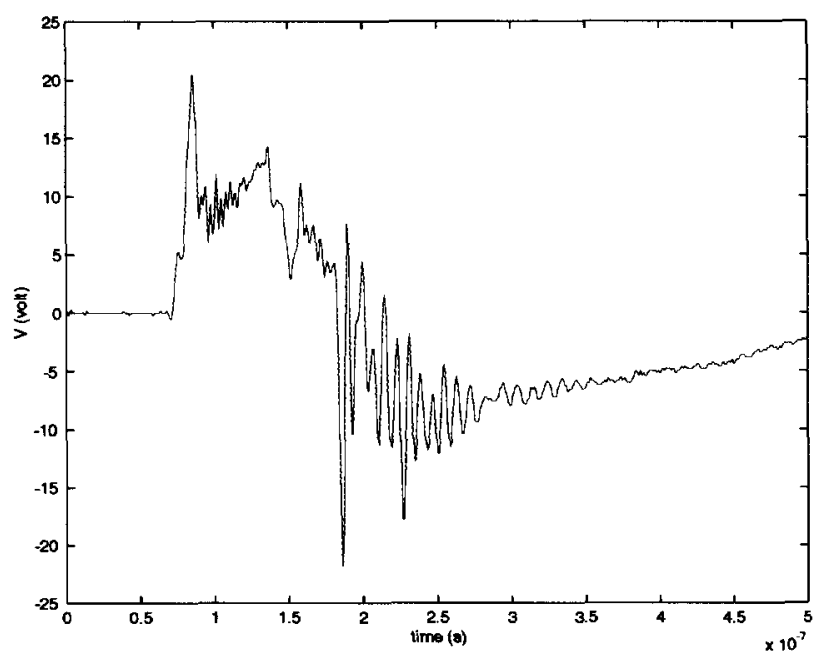

Figure 6. $75 \mathrm{~ns}$ input pulse at the gate terminal of a MOSFET.

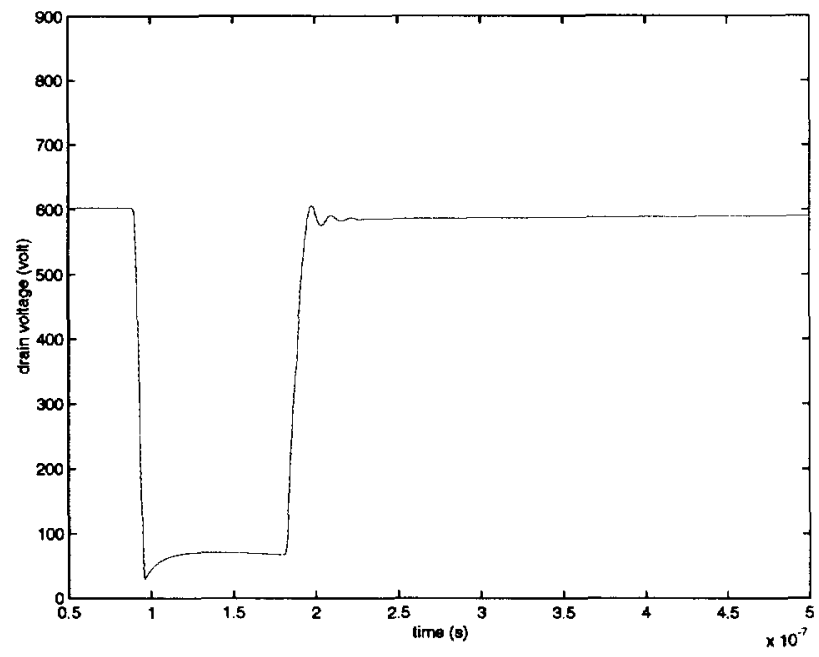

Figure 7. Voltage waveform at the drain terminal of a MOSFET for $75 \mathrm{~ns}$ input pulse.

Figure 8 shows the output voltage waveform at the load. The dashed curve represents the simulated load voltage. The waveform is very similar to the drain voltage waveform except that they differ by 600 volts. The load voltage waveform from the experimental measurements is displayed as a solid curve in Figure 8. The figure shows that the simulation results are in good agreement with the measurements except that there are overshoots at the end of the measured voltage waveform. The overshoots are caused by the magnetization current in the magnetic core. The cores require reset so that they do not saturate during a voltage pulse. The use of a reset circuit will roduce the voltage overshoot.

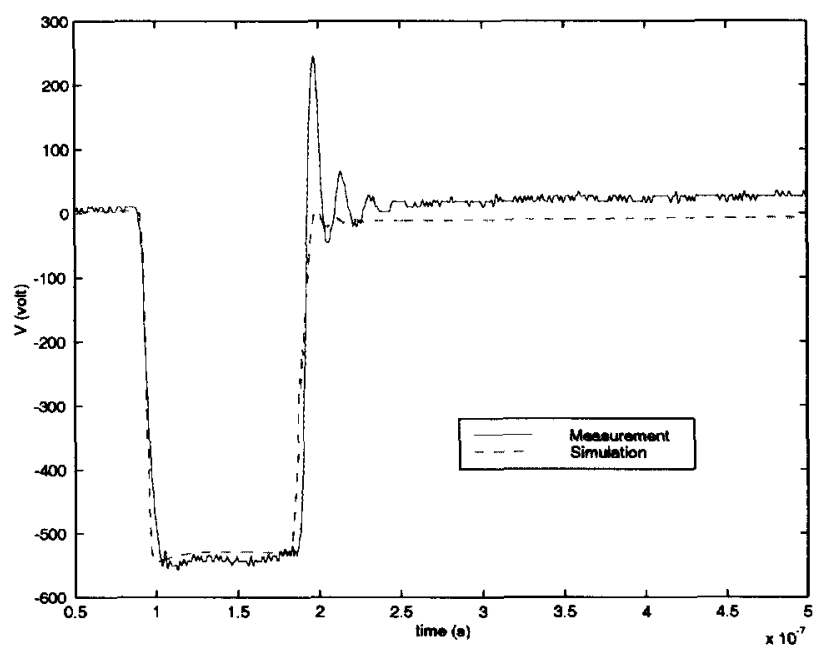

Figure 8. Comparison of simulation with measurements of the output voltage for $75 \mathrm{~ns}$ input pulse.

The circuit model is also used to simulate the output voltage for the case of 120ns input pulse. Figure 9 shows the 120ns input pulse at the gate terminal of a MOSFET. For the case of $120 \mathrm{~ns}$ input pulse, the capacitors are charged to $500 \mathrm{~V}$ initially. Figure 10 displays the waveform at the drain terminal of a MOSFET.

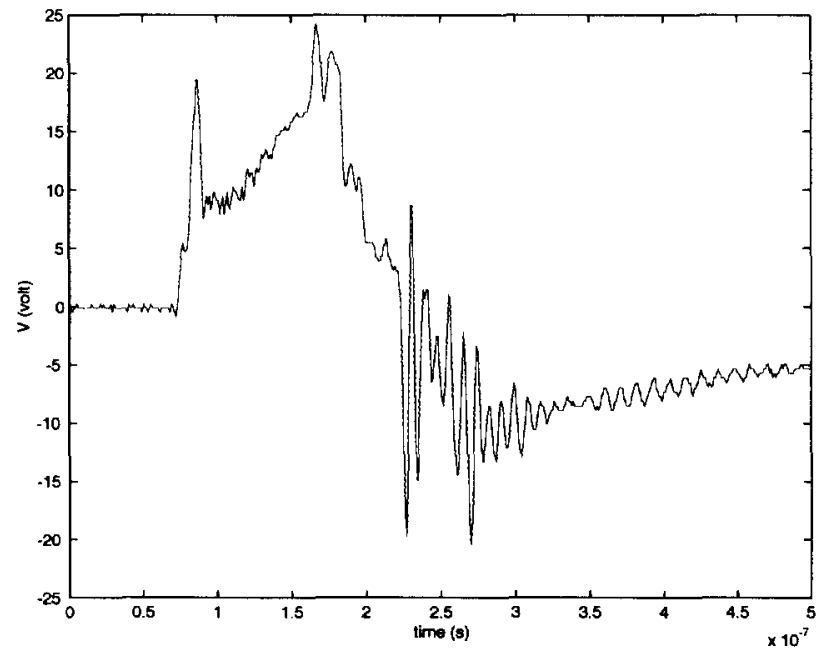

Figure 9. 120ns input pulse at the gate terminal of a MOSFET.

Figure 11 shows the output voltage waveform at the load. Again, the dashed curve represents the simulated load voltage. The waveform is very similar to the drain voltage waveform except that they differ by 500 volts. The load voltage waveform from the experimental measurements is 
displayed as a solid curve in Figure 11. Like the case for $75 \mathrm{~ns}$ input pulse, the simulation results are in good agreement with the measurements except for the overshoots at the end of the measured voltage waveform caused by the magnetization current in the magnetic core .

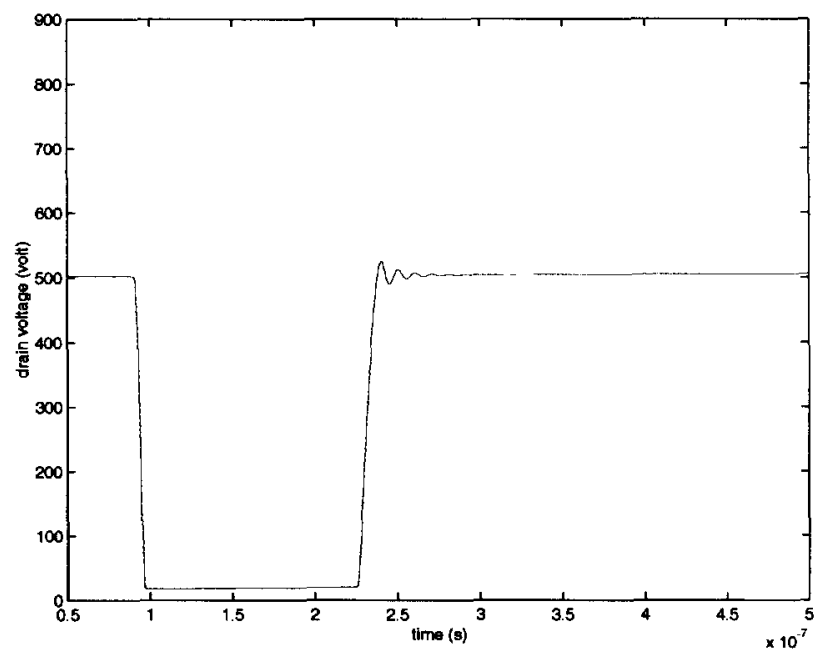

Figure 10. Voltage waveform at the drain terminal of a MOSFET for 120ns input pulse.

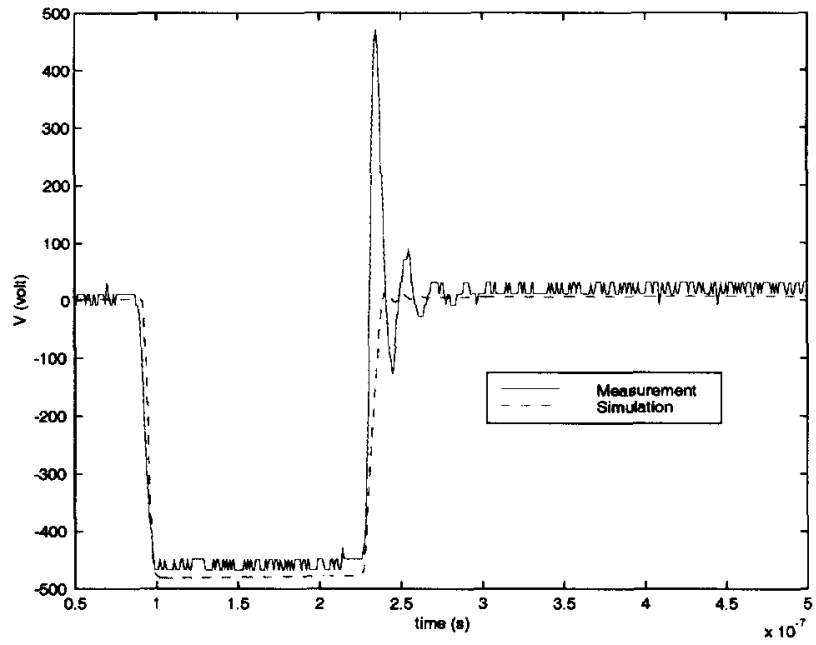

Figure 11. Comparison of simulation with measurements of the output voltage for $120 \mathrm{~ns}$ input pulse.

\section{IV.SUMMARY}

A circuit model of a prototype inductive adder kicker pulser modulator for a proton radiography system has been developed. Output voltage waveforms were simulated using the circuit model for different input pulse width. The simulation results are in good agreement with the measurements except for overshoots at the end of the measured voltage waveform. The overshoots are caused by the magnetization current in the magnetic core. The use of a reset circuit will reduce the voltage overshoot.

\section{REFERENCES}

[1] E. G. Cook, B. S. Lee, S. A. Hawkins, F. V. Allen, B. C. Hickman, and H. C. Kirbie, "Inductive-adder kicker modulator for DARHT-2”, $20^{\text {th }}$ International Linear Accelerator Conference, Monterey, CA, August 21-25, 2000.

[2] W. J. DeHope, Y. J. Chen, E. G. Cook, B. A. Davis, and B. Yen, "Recent advances in kicker pulser technology for linear induction accelerators", $12^{\text {th }}$ IEEE International Pulsed Power Conference, Monterey, CA, June 27-30, 1999.

[3] H. Kirbie, G. Caporaso, D. Goerz, R. Hanks, B. Hickman, B. Lee, C. Brooksby, and R. Saethre, "MHz repetition rate solid-state driver for high current induction accelerators", 1999 Particle Accelerator Conference, New York, NY, March 29-April 2, 1999. 